\begin{tabular}{ll} 
Kastamonu Eğitim Dergisi & \\
Kastamonu Education Journal & Başuru Tarihi/Received: 12.02 .2018 \\
Mart 2019 Cilt:27 Sayı:2 & Kabul Tarihi/Accepted: 21.09 .2018 \\
kefdergi.kastamonu.edu.tr & Dol: $10.24106 /$ kefdergi.2672 \\
\hline
\end{tabular}

\title{
Başarılı Okuyucular ile Öğrenme Güçlüğü Olan Öğrencilerin Metni Anlamak için Kullandıkları Bilişsel ve Üstbilişsel Stratejiler
}

\section{Cognitive and Metacognitive Strategies Used by Good Readers and Students with Learning Disabilities to Understand a Text}

\section{Öz}

\author{
Tahsin FIRAT ${ }^{1}$, Duygu KOÇAK ${ }^{2}$
}

Bu araştırmada, başarılı okuyucular ile öğrenme güçlüğü olan öğrencilerin okuma sürecinde kullanmış oldukları bilişsel ve üstbilişsel stratejiler karşılaştırmalı olarak incelenmiştir. Araştırma, 6.,7., ve 8. Sınıfa devam eden sekiz başarılı okuyucu ve sekiz öğrenme güçlüğü tanısı almış öğrenci ile gerçekleştirilmiştir. Öğrencilerin okuma öncesi, sırası ve sonrası kullandığı stratejileri ve davranışları belirlemek amacıyla odak grup görüşmesi yapılmıştr. Elde edilen veriler, içerik analizi yapılarak yorumlanmıştr. Araştırma sonucunda başarılı okuyucuların metni anlamak için okuma öncesi, sırası ve sonrası birçok strateji kullandıkları belirlenirken, öğrenme güçlüğü olan öğrencilerin çok az strateji kullandığı tespit edilmiştir.

Anahtar Kelimeler: Başarılı okuyucular, bilişsel ve üstbilişsel strateji, öğrenme güçlüğü.

\section{Abstract}

In this study, cognitive and metacognitive strategies used by good readers and students with learning disabilities in reading process were investigated comparatively. The study was conducted with eight students with learning disabilities, and with eight good readers continuing on the $6 \mathrm{th}, 7 \mathrm{th}$, and 8 th grades. Focus group interview was held to determine the strategies and behaviors the students used before, during and after the reading. The data were analyzed by using content analysis technique. Evidence was found that good readers used many strategies before, during and after reading to understand the text, while students with learning disabilites used very few strategies.

Keywords: Cognitive and metacognitive strategy, good readers, learning disability 


\section{Extended Summary}

Purpose and Significance : In order to reach the meaning during the reading process, readers have to be motivated for reading (Guthrie et.al., 2007; Taboada, Tonks, Wigfield and Guthrie, 2009), have a knowledge of text structure (Kendeou and Van Den Broek, 2007; León and Carretero, 1995) and use various cognitive and meta-cognitive strategies before, during and after reading that will enable them to complete the process successfully and act accordingly (Gersten, Fuchs, Williams and Baker, 2001; Swanson, 1999). Therefore, harmonious use of cognitive and meta-cognitive strategies will enable the reader to successfully complete the process for understanding what he/she has read. Accordingly, cognitive and meta-cognitive strategies may also be defined as behaviors displayed by good readers to reach the meaning. On the other hand, it is indicated that the failure to use cognitive and meta-cognitive strategies effectively is the fundamental reason with adverse impacts on the comprehension of students (Gaddy, 2004; Mastropieri, Scruggs and Graetz, 2003; Swanson and Vaughn, 2010). Students with learning disabilities make up an important section of these students (Gersten et al., 1998). It is put forth in the related literature that students with learning disabilities are defined as readers who contrary to good readers use cognitive and meta-cognitive strategies less or in an insufficient manner (Hallahan, Kauffman and Lloyd, 1996; Jitendra, Hoppes and Xin, 2000; Torgesen, 1982). It has been observed in the studies carried out that students with learning disabilities or weak readers use cognitive and meta-cognitive strategies much less or more ineffectively in comparison with good readers (Anastasiou and Griva, 2009; Botsas and Padeliadu; 2003; Gelen, 2003; Ehrlich, Kurtz-Costes and Loridant, 1993).

Knowledge on what students with learning disabilities lack will contribute to how they can acquire the comprehension skills they need (Anastasiou and Griva, 2009; Lau, 2006). In addition, it may also be important to analyze the strategies employed by students with successful comprehension skills in addition to the skills they display in order to teach these skills to students with learning disability (Hummel, 2000). In this regard, the objective of the study was to determine in a comparative manner the cognitive and meta-cognitive strategies of good readers and students with learning disability before, during and after the reading process.

Methods: "Homogeneous sampling" method from among the purposive sampling methods was used for determining the participants. The objective here was to define a distinctive sub-group by way of forming a small, homogeneous sample group (Yıldırım and Şimşek, 2005). Teacher opinions and academic success of students in the Turkish course were taken into consideration while selecting good readers, whereas students with learning disability were determined according to the criteria of being diagnosed with learning disability after which two groups of eight 6th, 7th and 8th grade students with ages varying between 11-15 were formed and focus group interviews were completed separately.

Semi-structured interview form was used during focus group interview. A sample text from among those determined prior to the study was given to the participants during focus group interviews and they were asked to examine these texts. The participants were then asked the following questions: 1) what do you notice first in a text? 2) what do you do first to understand a text?" 3) Which part do you read first in a text? 4) What do you do to understand the text better 5) what do you do when there are parts you do not understand.

The interviews were recorded using a video camera. The recording lasted 61 minutes for good readers and 52 minutes for students with learning disability. Content analysis method was used for the acquired data which encompasses stages such as determining the basic patterns, coding and categorization (Yıldırım and Şimşek, 2011).

Findings and Discussion : The findings of the study indicate that students with learning disabilities use very low or insufficient levels of cognitive and meta-cognitive strategies before, during and after reading. On the other hand, it was also determined that good readers employ more strategies before, during and after reading in order to understand the given text. This result is in accordance with the results of previous studies (Anastasiou and Griva, 2009; Botsas and Padeliadu; 2003; Gelen, 2003; Ehrlich, Kurtz-Costes and Loridant, 1993).

When the behaviors of participants before reading were examined, it was put forth that while good readers use various strategies for activating their previous knowledge and make estimations about the text so that they can understand the text; students with learning disabilities make estimations based only on visuals. In addition, good readers preferred longer texts that they are interested on, whereas students with learning difficulty generally focused on short texts related with their course. This can be explained by the negative experiences of students with learning disabilities and hence their low motivation.

When the behaviors of participants during the reading process were examined, it was determined that good readers use strategies for making estimations, visual evaluation and comparison with past data, while students with learning disabilities only ask the meaning of the words they do not know in order to understand the text being read. Based on this result, it was observed that good readers use strategies for monitoring their comprehension and to make these information meaningful, whereas students with learning disability focus on the meaning of the words in the text thereby losing the content integrity of the text which prevents them from relating the information in the text with their previous knowledge thus resulting in an understanding.

\section{Conclusions and Proposals}

It was determined in summary when all these results were evaluated that good readers combine many cognitive and meta-cognitive strategies and select longer and more difficult texts. On the other hand, it was also determined that students with learning disabilities do not use many cognitive and meta-cognitive strategies before, during and after reading and that they select short and easier texts. This study has various limitations that should be taken into consideration when evaluating its results. 


\section{Giriş}

Okuma, öğrencilerin hem akademik başarıları hem de günlük yaşamdaki birçok öğrenmeyi gerçekleştirebilmeleri için gerekli olan önemli bir beceridir. Başarılı bir okuma süreci; okuyucuların yazılı metinlerde yer alan kelimeleri uygun ortografik, sesbilgisel, morfolojik bilgi ve becerilerini kullanarak çözümlemeleri, ardından çözümlenen kelimeleri var olan sözcük dağarcıkları, önceki bilgi ve deneyimleri ile bağdaştırarak anlamlandırmaları, sonrasında ise anlamlandırdıkları kelimelerden oluşan cümleleri sözdizimsel özellikleri bağlamında analiz edip verilmek istenen mesaja ulaşabilmeleri olarak tanımlanmıştır (Güldenoğlu, Kargın ve Miller, 2013). Bu bağlamda, okuduğunu anlama okuma sürecinin nihai hedefi (Edmons vd., 2009; Mahdavi ve Tensfeldt, 2013; Tannenbaum, Torgesen ve Wagner, 2006) veya okumanın özü olarak ifade edilebilir (Durkin, 1993; Ford ve Opitz, 2011; Maine, 2013).

Okuyucuların okuma sürecinde anlama ulaşabilmeleri için, ayrıca okumaya karşı güdülenmeleri (Guthrie vd., 2007; Taboada, Tonks, Wigfield ve Guthrie, 2009), metin yapısı bilgisine sahip olmaları (Kendeou ve Van Den Broek, 2007; León ve Carretero, 1995), aynı zamanda bu süreci başarılı bir şekilde tamamlamalarını ve buna uygun hareket etmelerini sağlayacak okuma öncesinde, sırasında ve sonrasında çeşitli bilişsel ve üstbilişsel stratejiler kullanmaları gerekmektedir (Gersten, Fuchs, Williams ve Baker, 2001; Swanson, 1999). Bu süreçte okuyucular bilişsel stratejileri belirli bir anlama ulaşmaya yardımcı olmak için kullanırken, üstbilişsel stratejileri ise bu hedefe ulaşıldığından emin olmak için kullanırlar (Livingston, 2003). Diğer bir ifadeyle, bilişsel stratejiler anlamayı sağlayan adımlar olarak ifade edilirken, üstbilişsel stratejiler bu adımların ne kadar doğru, etkili ve amaca uygun olduğunun izlenilmesini ve yeniden düzenlenmesini içerir (Fırat, 2017). Dolayısıyla bilişsel ve üstbilişsel stratejilerin birlikte ve uyumlu bir şekilde kullanılması okuyucunun okuduğunu anlama sürecini başarılı bir şekilde gerçekleşmesini sağlayacaktır. Bu doğrultuda bilişsel ve üstbilişsel stratejiler için başarılı okuyucuların metni anlamada sergiledikleri davranışlar da denilebilir. Bilişsel stratejilere metinle ilgili tahminde bulunma, önceki bilgileri aktifleştirme, ana fikri bulma, metindeki bilgi ile önceki bilgilerini birleştirme, metin yapısını belirleme ve özetleme örnek gösterilebilir (Buxton, 2017). Üstbilişsel stratejiler ise okuma öncesinde metinin uzunluk, yapı, karmaşıklık düzeyini değerlendirme, okuma süreçlerinin planını oluşturma, okuma sırasında okuma hızlarını ayarlama, anlamadığı yerleri tekrar okuma, not alma, önemli yerlerin altını çizme ve anlamadığı kelimeye sözlükten bakma veya bağlam içerinde anlamı çıkarma, okuma sonrasında ise metin hakkında düşünmeye devam etme, kendine sorular sorma, önemli gördüğü veya anlamadığı yerleri tekrar okuma sayılabilir (Mason, 2004; Pressley ve Gaskins, 2006). Başarılı okuyucular, okuma öncesi, sırası ve sonrası stratejileri okuma sürecinde bir arada ve uyumlu kullanırlar (Espinoza ve Márquez Cruz, 2015; Pressley, 2002; Pressley ve Afflerbach, 1995). Diğer taraftan bilişsel ve üstbilişsel stratejilerin etkin bir şekilde kullanılamamasının, öğrencilerin anlamalarını olumsuz etkileyen temel neden olduğu belirtilmektedir (Gaddy, 2004; Mastropieri, Scruggs ve Graetz, 2003; Swanson ve Vaughn, 2010). Bu öğrencilerin önemli bir kısmını da öğrenme güçlüğü olan öğrenciler oluşturmaktadır (Gersten vd., 1998). ilgili alanyazında öğrenme güçlüğü olan öğrencilerin başarılı okuyucuların tersine okuma öncesi, sırası ve sonrası bilişsel ve üstbilişsel stratejileri az veya yetersiz kullanan pasif okuyucular olarak ifade edilmektedir (Hallahan, Kauffman ve Lloyd, 1996; Jitendra, Hoppes ve Xin, 2000; Torgesen, 1982).

Yapılan araştırmalarda da, öğrenme güçlüğü olan öğrenciler veya zayıf okuyucuların başarılı okuyuculara göre bilişsel ve üstbilişsel stratejileri çok az veya etkisiz kullandıkları görülmüştür (Anastasiou ve Griva, 2009; Botsas ve Padeliadu; 2003; Gelen, 2003; Ehrlich, Kurtz-Costes ve Loridant, 1993; Kavale ve Schreiner, 1979; Kletzien, 1991; Kuruyer ve Özsoy, 2015; Lau, 2006; Lau ve Chan, 2003; Tilstra, 2007; Wigent, 2013). Lau (2006), tarafindan yapılan bir çalışmada, başarılı okuyucuların okuma amaçlarının farkında olduklarını, anahtar kelimeleri belirleyebildiklerini, ana fikri oluşturduklarını, önceki bilgilerini aktifleştirdiklerini, karşılaştırma ve çıkarımlar yaptıklarını, okuma süreçlerini izlediklerini ve karşılaştıkları problemleri çözdüklerini belirlemiştir. Buna karşın zayıf okuyucuların okumaya karşı isteksiz olduklarını, herhangi bir anlama stratejisi uygulamadan, sadece metni kelime kelime okuduklarını tespit etmiştir. Ehrlich, Kurtz-Costes ve Loridant (1993) ise, başarılı okuyucuların zayıf oyuculara göre kelime tanıma ölçütünde daha yüksek puan aldığını, daha zengin üstbilişsel bilgiye sahip olduklarını ve akademik yetenekleri hakkında daha olumlu inançlara sahip olduklarını belirlemiştir. Araştırmada ayrıca kelime bilgisi ve üstbilişin, okuduğunu anlama becerisi üzerinde belirleyici olduğu tespit edilmiştir.

Bütün bu araştırmalar dahilinde, yapılmış çalışmaların daha çok başarılı okuyucular ile zayıf okuyucuların anlama becerilerini karşılaştırma üzerine yoğunlaştğı görülmektedir. Alanyazında yer alan öğrenme güçlüğü tanısı almış öğrencilerle başarılı okuyucuların anlama stratejilerini kullanmalarını karşılaştırmaya yönelik çalışmaların sınırlı sayıda olduğu görülmektedir. Öğrenme güçlüğü yaşayan öğrencilerin ne tür eksikliklerinin olduğunun bilinmesi, ihtiyaç duydukları anlama becerilerinin nasıl kazandııılacağına katkıda bulunacaktır (Anastasiou ve Griva, 2009; Lau, 2006). Ayrıca başarılı anlama becerisine sahip öğrencilerin okuma sürecinde ne yaptıkları, ne gibi stratejiler uyguladıkları ve ne tür beceriler 
gösterdiklerinin analiz edilmesi, öğrenme güçlüğü yaşayan öğrencilere de bu becerilerin öğretilmesinde ve uygulanmasında önemli olabilir (Hummel, 2000). Bu tartş̧malar ve alanyazındaki konuya ilişkin eksiklikler göz önünde bulundurularak bu araştırmada; başarılı okuyucular ile öğrenme güçlüğü olan öğrencilerin okuma sürecinde; öncesinde, sırasında ve sonrasında gösterdikleri bilişsel ve üstbilişsel stratejileri karşılaştırmalı olarak belirlenmesi amaçlanmıştı. Bu amaç doğrultusunda başarılı okuyucular ile öğrenme güçlüğü olan okuyucuların;

- Okuma öncesinde sergilediği davranışlar

- Okuma sırasında sergilediği davranışlar ve

- Okuma sonrasında sergilediği davranışlar nelerdir sorularına yanıt aranarak öğrencilerin kullandıkları bilişsel ve üstbilişsel stratejiler karşılaştırılmıştır.

\section{Yöntem}

\section{Araştırmanın Modeli}

Bu araştırma, okuma sürecindeki bilişsel süreçleri olduğu gibi ortaya çıkarması açısından nitel araştırmaların içinde yer alan bir tarama çalışmasıdır (Yıldırım ve Şimşek, 2011).

\section{Katilımcılar}

Araştırmada katılımcıların belirlenmesinde, amaçlı örnekleme tekniklerinden "benzeşik (homojen) örnekleme" tekniği kullanılmıştır. Buradaki amaç, küçük, benzeşik bir örneklem oluşturma yoluyla belirgin bir alt grubu tanımlamaktır (Yıldırım ve Şimşek, 2011). Başarılı okuyucular belirlenirken öğretmen görüşü ve öğrencilerin Türkçe dersi akademik başarısı göz önünde bulundurulmuştur, öğrenme güçlüğü olan öğrenciler ise Rehberlik Araştırma Merkezi tarafindan öğrenme güçlüğü tanısı alma kriterine göre belirlenerek yaşları 11-15 arasında değişen 6., 7. ve 8. sınıf öğrencilerinden, sekizer kişilik iki grup oluşturularak, ayrı ayrı odak grup görüşmesi gerçekleştirilmiştir.

Tablo 1. Katilımcıların özellikleri

Başarılı okuyucular (B) Öğrenme güçlüğü olan okuyucular (O)

\begin{tabular}{|c|c|c|c|c|c|c|c|c|c|c|c|c|c|c|c|c|}
\hline Katilımcılar & $\vec{\infty}$ & กี & $\ddot{\infty}$ & ఫ్ & $\stackrel{\llcorner}{\infty}$ & $\stackrel{\infty}{\infty}$ & $\hat{\infty}$ & $\stackrel{\infty}{\infty}$ & $: 0-1$ & $: 0 ี$ & $: 00$ & : & $: 0$ & $: 0$ & $: 0$ & $: 0$ \\
\hline Cinsiyet (K/E) & $\mathrm{K}$ & $\mathrm{K}$ & $\mathrm{E}$ & $\mathrm{K}$ & $\mathrm{E}$ & $\mathrm{E}$ & $\mathrm{K}$ & $\mathrm{E}$ & $\mathrm{E}$ & $\mathrm{E}$ & $\mathrm{K}$ & $\mathrm{K}$ & $\mathrm{E}$ & $\mathrm{K}$ & $\mathrm{E}$ & $\mathrm{E}$ \\
\hline Sınıf Düzeyi (6./7./8.) & 6 & 6 & 6 & 7 & 7 & 7 & 8 & 8 & 6 & 6 & 6 & 7 & 7 & 8 & 8 & 8 \\
\hline Yaş & 11 & 11 & 12 & 12 & 13 & 13 & 14 & 15 & 12 & 12 & 13 & 13 & 14 & 14 & 15 & 15 \\
\hline
\end{tabular}

Çalışmada Adıyaman ilinde Milli Eğitim Bakanlığı'na bağlı devlet okullarında öğrenim görmekte olan sekiz öğrenme güçlüğü tanısı almış ile sekiz başarılı okuyucu olmak üzere toplam 16 öğrencinin görüşüne başvurulmuştur.

\section{Verilerin Toplanması}

Araştırmada verilerin toplanması için odak grup görüşmesi tekniği kullanılmıştı. Odak grup görüşmesi sırasında yarı yapılandırılmış bir görüşme formu kullanıımıştı. Geliştirilen yarı yapılandırılmış görüşme formu sorularının hazırlanmasında; soruların açık, net, anlaşılır ve yönlendirici olmamasına dikkat edilmiştir (Bogdan ve Biklen, 1992). Görüşme soruları hazırlandıktan sonra bir dil bilgisi uzamanı ve bir ölçme ve değerlendirme uzmanının görüşü alınmış ve önerileri doğrultusunda düzenlenmiştir. Katılımcıların odak grup görüşmesi ile okuma esnasında sergiledikleri bilişsel süreçleri daha iyi ortaya çıkartabilmeleri açısından örnek okuma metinleri kullanılmıştı. Okuma metinlerinin belirlenmesinde yaş grubu, metnin konusu (ilgi çekici olup olmaması), metnin zorluğu, kelime sayısı, metnin görsel içerip içermemesi kriterleri göz önünde bulundurulmuştur. Görüşme video kamera ile kaydedilmiştir. Başarılı okuyucuların kaydı 61 dakika, öğrenme güçlüğü olan öğrencilerin kayıtları 52 dakika sürmüştür.

\section{Verilerin Analizi}

Odak grup görüşmesinden elde edilen verilerin analizinde içerik analizi en uygun yöntemdir (Kitzinger ve Farquhar, 1999). Elde edilen veriler üzerinde temel örüntüleri saptama, kodlama ve kategorilere ayırma süreçlerini kapsayan içerik analizi yapılmıştı (Yıldııı ve Şimşek, 2011). Analiz sürecinde öncelikle kodlama kuralları belirlenerek veriler kodlanmış ve kategoriler her iki araştırmacı tarafindan yapılmıştır. Analizleri iki araştırmacı tarafindan yapılarak araştırmacı çeşitlemesi sağlanmıştı (Johnson, 1997). Farklı kodlayıcıların yapmış oldukları kodlamalar arasındaki uyum Miles ve Huberman (1994) tarafindan önerilen uyum indeksi ile hesaplanmıştı. İki farklı kodlayıcı tarafindan elde edilen sonuçlar arasındaki araştırmacılar arası güvenirlik 0.79 olarak, her bir kodlayııının farklı zamanlarda yaptığı kodlamalar 
arasındaki zaman açısından güvenirlik 0.82 olarak elde edilmiştir. Raporlaştırmada katılımcıların kimliğinin gizli tutulması için katlımcılar için, B1 (birinci başarılı okuyucu), Ö1 (birinci öğrenme güçlüğü olan okuyucu) şeklinde kodlamalar yapılmıştr.

\section{Bulgular ve Yorumlar}

Öğrencilerin bilişsel ve üstbilişsel stratejileri kullanmaları odak grup görüşmesi ile değerlendirilmiştir. Aşağıda elde edilen bulgular ve yorumları sunulmuştur. Başarılı okuyucuların okuma öncesi davranışları neler olduğuna ilişkin bulgular Tablo 2'de sunulmuştur.

Tablo 2. Başarılı okuyucuların okuma öncesi davranışları

\begin{tabular}{lllc}
\hline Tema & Kategori & \multicolumn{1}{c}{ Katılımcılar } & $f$ \\
\hline Geçmiş bilgileri aktif & Görsel inceleme & B1, B2, B3, B4, B5, B6, B7, B8 & 8 \\
kılma & Önceki bilgileri hatırlama & B2, B3, B5, B6, B8 & 5 \\
\hline \multirow{3}{*}{ Metin tahmini } & Görsele bağlı metin tahmini* & B1, B2, B3, B4, B5, B6, B7, B8 & 8 \\
& Başlığa bağlı metin tahmini & B1, B2, B4, B5, B6, B7, B8 & 7 \\
& Metne göz gezdirerek konu tahmini & B1, B4, B5, B7, B8 & 5 \\
\hline \multirow{2}{*}{ Metin tercihi } & Görsel içeren metin tercihi* & B1, B2, B3, B4, B5, B6, B7, B8 & 8 \\
& Uzun metin tercihi & B1,B6, B8 & 3 \\
\hline \multicolumn{2}{c}{ * Başarılı okuyucularda ve öğrenme güçlüğü yaşayan okuyucularda okuma öncesi süreçte gözlenen ortak davranış } & 6 \\
\hline
\end{tabular}

Başarılı okuyucuların ifadelerine bağı olarak geçmiş bilgileri aktif kılma, metin tahmini ve metin tercihi temaları ve bu temalar altında sekiz kategori elde edilmiştir. Aşağıda elde edilen temalar ve kategoriler açıklanmıştır.

\section{Geçmiş bilgileri aktif kılma}

\section{Görsel inceleme (f:8)}

Başarılı okuyucular, okuma öncesinde okuma metininde görsel (resim) sunulması durumunda okumaya geçmeden önce görseli inceledikleri, görselin çağrıştırdıkları ve ona dair neler bildiklerini, daha önce buna benzer görsel içeren bir metin okuyup okumadıklarını hatırlamaya çalıştkklarını ifade etmişlerdir.

B1: “...önce verilen resimlere bakarım. O resim benim aklıma neler getiriyor onları düşünürüm”.

\section{Önceki bilgileri hatırlama (f:5)}

Okuma öncesinde, okuyacakları metinin konusu hakkında neler bildiklerini daha önce bu konuda neler okuduklarını hatırlamaya çalıştıklarını ifade etmişlerdir.

B2: “...bir şeyle ilgili yazı varsa mesela okuduğum onunla ilgili daha önce bir şey okudum mu diye düşünürüm önce. Belki aynısıdır belki çok benziyordur. Onu düşünürüm hatılarım."

\section{Metin tahmini}

\section{Görsele bağlı metin tahmini (f:8)}

Okuyucuların sekizi metinde bir görsel verilmesi durumunda bu görseli inceleyerek o konuda neler bildiklerini hatırlamanın yanında, metinde nelerin anlatılmış olabileceğini tahmin etmeye çalıştılarını ifade etmişlerdir.

B3: “...bazen bir tane resme bakınca bile ne anlatıldığı anlaşılıyor. Bir şeyi okurken resmine bakıyorum orada ne anlatlıyordur karar veriyorum. Resme bakarak hikayeyi tahmin ediyorum."

\section{Başlığa bağlı metin tahmini (f:7)}

Okuyucuların yedisi metnin başlığının metinde anlatılanlar hakkında ipucu verdiğini, okumaya başlamadan önce metinde nelerin anlatılıyor olduğunu tahmin etmeye çalıştıklarını ifade etmişlerdir.

B4: “...kitabın adına bakııınca onun ne hakkında olduğu hemen anlaşılır. Yazılarda da öyle. Başlığı okuyorum önce sonra o yazıda ne anlatılmıştır diye düşünüyorum"

Metne göz gezdirerek metin tahmini (f:5)

Başarılı okuyucuların beşi, öncelikle hızlıca bir göz gezdirerek gözlerine çarpan kelimelerden yola çıkarak ne anlatılı- 
yor olduğunu tahmin ettiklerini ardından okuma sürecine geçtiklerini ifade etmişlerdir.

B5: “...önce hızlıca bakıyorum sonra bazı yerlerde ne anlatyyordur burada diye akıl yürütüyorum.”

\section{Metin tercihi}

Görsel içeren metin tercihi (f:8)

Başarılı okuyucuların sekizi, görsel içeren metinleri okumanın daha eğlenceli olduğu ve anlatılanları canlandırmanın daha kolay ve anlaşılır olduğu gerekçesiyle tercih ettiklerini ifade etmişlerdir.

B6: “... resimli kitaplar yazılar daha eğlenceli olur. Resimlerle anlatılanlar anlatılıyorsa daha güzel öğrenilir” Uzun metin tercihi (f:3)

Başarılı okuyucuların üçü kendilerine tercih hakkı verildiğinde kelime sayısı fazla olan, daha uzun metinleri tercih edeceklerini belirtmişlerdir. Uzun metinlerde anlatılan bilginin daha fazla olacağı dolayısıyla daha fazla bilgi edineceklerini ifade etmişlerdir.

B8: “... daha kalın olan kitaplarda, uzun olan yazılarda daha çok bilgi olur. Hem daha fazla bilmediğim kelime olur onları da öğrenmiş olurum bunları okumayı isterim."

ilgi çekici içerikte olan metin tercihi (f:6)

Başarılı okuyucuların altısı özellikle ilgilerini çeken konularla ilgili detaylı bilgi edinmek isteyeceklerini bu nedenle ilgi alanlarına dair metinleri okumayı tercih edeceklerini ifade etmişlerdir.

B7: “ ben atomlarla ilgili yazıları seviyorum. Konusu bu olunca bunları okumak istiyorum.

Tablo 3’te öğrenme güçlüğü olan okuyucuların okuma öncesinde sergiledikleri davranışlar sunulmuştur.

Tablo 3. Öğrenme güçlüğü yaşayan okuyucuların okuma öncesi davranışları

\begin{tabular}{llll}
\hline Tema & Kategori & Katlımcılar & $f$ \\
\hline Metin tahmini & Görsele bağlı metin tahmini* & Ö2, Ö3, Ö4, Ö6, Ö7 & 5 \\
\hline \multirow{3}{*}{ Metin tercihi } & Görsel içeren metin tercihi* & Ö1, Ö2, Ö3, Ö4, Ö5, Ö6, Ö7, Ö8 & 8 \\
& Kısa metin tercihi & Ö1, Ö3, Ö4, Ö5, Ö6, Ö7, Ö8 & 7 \\
& Dersle ilgili metin tercihi & Ö1, Ö3, Ö4, Ö5, Ö7 & 5 \\
\hline
\end{tabular}

Odak grup görüşmesi ile elde edilen verilerin analizi sonucunda metin tahmini ve metin tercihi temaları ve bu temalar altında dört kategori elde edilmiştir. Aşağıda elde edilen temalar ve kategoriler açıklanmıştır.

\section{Metin tahmini}

\section{Görsele bağlı metin tahmini (f:5)}

Öğrenme güçlüğü yaşayan öğrencilerin beşi okuma öncesi süreçte kendilerine sunulan metinde görsel yer alması durumunda öncelikle görseli inceledikleri ve görsele bağlı olarak metinde anlatllanlara dair tahminde bulundukları bulgusu elde edilmiştir.

Ö2: “...hikayelerde resimler olduğunda ona bakınca anlaşılıyor ne anlatthğı. Mesela deniz resmi var balıklar ölmüş plajda yatıyor su pis görünüyor. O zaman deniz kirlendiği için balıkların öldüğünü anlatıyordur yazıda"

\section{Metin tercihi}

\section{Görsel içeren metin tercihi (f:8)}

Öğrenme güçlüğü yaşayan okuyucuların sekizi okumak için tercih edecekleri metinlere dair görüşleri incelendiğinde, görsel (resim) içeren metinleri tercih ettikleri sonucuna ulaşılmıştır.

Ö1: “...resimli olan yazılar, hikaye kitapları daha güzel oluyor. Hem resimlere bakınca da anlaşılıyor ne an-

lattı̆ı. Kitap alırken resimli mi diye bakarım."

Kısa metin tercihi (f:7)

Okuyucuların yedisi kısa metinlerin daha çabuk okunup biteceği ve daha kolay olacağı bu nedenle kısa metinleri tercih edeceklerini ifade etmişlerdir. 
Ö4: “...sıkıldığım için kısa olan yazıları okurum. Eğer hiç okumama şansım varsa hiç okumam. Ama okuyacaksın dediyse öğretmen kısa olanları okurum"

Dersle ilgili metin tercihi (f:5)

Öğrenme güçlüğü yaşayan okuyucuların beşi, metin okumak zorunda olduklarında bunun dersle ilgili olmasını tercih ettiklerini, en azından okuyacakları metnin kendilerine derste faydası olduğunu belirtmişlerdir. Öğrenme güçlüğü yaşayan öğrencileri dersle ilgili olmayan metinleri okumanın faydasız olacağı görüşünü bildirmişlerdir. Aşağıda örnek ifadelere yer verilmiştir.

Ö7: “...okurken takılıyorum hep kelimelere. Sevmiyorum okumayı uykumu da getiriyor hemen. Dersle ilgili kitapları okumak zorundayız. O zaman ben de mecburen okuyacaksam ders kitaplarını okurum."

Sonuç olarak, başarılı öğrenciler ile öğrenme güçlüğü olan öğrencilerin okuma öncesinde ortaya koydukları davranışlar ve kullandıkları bilişsel ve üstbilişsel stratejiler incelendiğinde; başarılı okuyucuların metni anlamak için okuma öncesinde çok çeşitli bilişsel ve üstbilişsel strateji kullandığı, uzun ve ilgilerine göre metinler seçtikleri belirlenmiştir. Buna karşın öğrenme güçlüğü olan öğrencilerin pek fazla bilişsel ve üstbilişsel strateji kullanmadığı, kısa ve dersleriyle ilgili metinler seçtikleri görülmüştür.

Başarılı okuyucuların okuma sırasında sergiledikleri davranışlara ilişkin elde edilen bulgular Tablo 4'te sunulmuştur.

Tablo 4. Başarılı okuyucuların okuma sırasında sergiledikleri davranışlar

\begin{tabular}{|c|c|c|c|}
\hline Tema & Kategori & Katilımcılar & $f$ \\
\hline \multirow{2}{*}{ Tahmin } & Sonu tahmin etme & $\mathrm{B} 1, \mathrm{~B} 2, \mathrm{~B} 4, \mathrm{~B} 5, \mathrm{~B} 7, \mathrm{~B} 8$ & 6 \\
\hline & Kelimelerin anlamını tahmin & B1, B5, B6, B7, B8 & 5 \\
\hline \multirow{4}{*}{ İzleme } & Kelimelerin ve cümlelerin altını çizme & B2, B3,B5, B6, B7 & 5 \\
\hline & Tekrar okuma & $\mathrm{B} 2, \mathrm{~B} 3, \mathrm{~B} 4, \mathrm{~B} 6, \mathrm{~B} 8$ & 5 \\
\hline & Kendine soru sorma & $\mathrm{B} 1, \mathrm{~B} 2, \mathrm{~B} 4, \mathrm{~B} 5, \mathrm{~B} 8$ & 5 \\
\hline & Önemli kısımları yavaş okuma & B3, B4, B6, B8 & 4 \\
\hline \multirow{2}{*}{ Görsel değerlendirme } & Görsel metin uyumunu inceleme & B1, B2, B5, B6, B7 & 5 \\
\hline & Zihinde canlandırma & $\mathrm{B} 1, \mathrm{~B} 2, \mathrm{~B} 3, \mathrm{~B} 4, \mathrm{~B} 5, \mathrm{~B} 6, \mathrm{~B} 7, \mathrm{~B} 8$ & 8 \\
\hline Geçmiş bilgilerle kıyaslama & Önceki bilgilerle karşılaştırma & B1, B3, B5, B6, B7, B8 & 6 \\
\hline
\end{tabular}

Başarılı okuyucuların ifadelerine bağlı olarak tahmin, izleme, görsel değerlendirme, geçmiş bilgilerle kıyaslama temaları ve bu temalar altında dokuz farklı kategori elde edilmiştir.

\section{Tahmin}

\section{Sonu tahmin etme (f:6)}

Başarılı okuyucuların altısı kendilerine sunulan metni okurken bir yanda da anlatılanlardan hareketle hikayenin sonunu tahmin ettiklerini böylece daha istekli okuduklarını ve daha iyi anladıklarını ifade etmişlerdir.

B1: “...okurken hep sonunda ne olacağını düşünüp tahmin ederim. Sonunda hep doğru bilmiş olurum.”

Kelimelerin anlamın tahmin etme (f:5)

Başarılı okuyucuların beşi okuma esnasında anlamını bilmedikleri kelimelerle karşılaştıklarında cümlenin bağlamından ve anlatılanlardan yola çıkarak kelimenin anlamına ilişkin çıkarımda bulunduklarını bir diğer ifadeyle tahmin ettiklerini ifade etmektedirler.

B1: “...ne demek olduğunu bilmediğim kelimler oluyor ama sözlükten bakmadan önce kendim bulmaya çalışıyorum. Anlatılanlara bakıyorum sonra o kelime ne demek anlamaya çalışıyorum."

\section{İzleme}

\section{Kelimelerin ve cümlelerin altını çizme (f:5)}

Başarılı okuyucuların beşi okuma sürecinde okudukları metinde önemli bilgilerin verildiği ya da önemli detayların verildiği cümlelerin altını çizdiklerini böylece daha iyi anladıklarını ifade etmişlerdir.

B3: “...ben kitap okurken kurşun kalemle altnnı çiziyorum okuduğum yerin. Bazı öğretmenler kızıyor böyle yaptı̆ı̆ında ama altını çizince daha iyi anlıyorum ben" 
Tekrar okuma (f:5)

Başarılı okuyucuların beşi okuma esnasında önemli olan cümleleri baştan okuduklarını, o cümlede anlatılanı tam olarak anladıklarında diğer cümleleri okumaya devam ettiklerini ve bunun daha iyi anlamalarını sağladığını belirtmişlerdir.

B2 : “...zor oluyor bazen okuduklarım. Mesela bir cümleyi okuyorum o cümleden aklımda bir şey kalmıyor anlamıyorum ne anlattğını. O zaman tekrar anlayana kadar okurum öyle şeyleri"

Kendine soru sorma $(f: 5)$

Başarılı okuyucuların beşi, metin okuma sürecinde okuma ilerledikçe bir yandan okuyup bir yandan da okudukları kısımlarla ilgili kendilerine sorular sorduklarını ve anlayıp anlamadıklarını kontrol ettiklerini ifade etmişlerdir.

B4: “...bazen öğretmenimiz bir okuduktan sonra anladık mı anlamadık mı diye bize soru soruyor. Soruların cevaplarını biliyorum ben hep. Ben de okurken hemen soru soruyorum kendime okuduğumla ilgili."

Önemli kısımları yavaş okuma (f:4)

Başarılı okuyucuların dördü, okurken okudukları metinde önemli kısımlara geldiklerini düşündüklerinde okumalarını yavaşlatarak tane tane okuduklarını, böylece daha iyi anlayıp önemli kısımlardaki hiçbir detayı kaçırmadıklarını ifade etmişlerdir.

B6: “...önemli yerleri hızlı okursam daha az anlıyorum. Yavaş yavaş kelime kelime okurum oraları okurken.

O zaman daha iyi anlarım..."

\section{Görsel değerlendirme}

Görsel metin uyumunu inceleme (f:5)

Başarılı okuyucuların beşi, metin okuma esnasında okudukları metinden anladıkları ya da edindikleri bilgiler ile metinde verilen görselin birbiri ile uyumlu olum olmadığını kontrol ettiklerini ifade etmişlerdir.

B7: “...bazen kitaplarda da resimler oluyor. Resimdekinin kıyafetiyle anlatlanlardaki kıyafeti farklı oluyor. Ben bunlara dikkat ederim. Verilen resimde görünenlerle hikayede anlatılan aynı mı diye karşılaştırmasını yaparım"

Zihinde canlandırma (f:8)

Başarılı okuyucuların sekizi, okuma esnasında okudukları metinde anlatılanları zihinlerinde canlandırdıklarını, eğer anlatılan bir hikaye ise ve bir kahramanı varsa kendilerini onun yerine koyarak olayı yaşadıklarını ifade etmişlerdir.

B5: “...okuduğum her şeyi aklımda çizgi film gibi oynatıım ben. Hikayelerde kahramanları ve diğer kişileri nasıl anlattlarsa öyle o kıyafetlerle hayal ederim"

\section{Geçmiş bilgilerle kıyaslama}

Önceki bilgilerle karşılaştırma (f:6)

Başarılı okuyucuların altısı, okuma esnasında metinden edindikleri bilgiler ile edindikleri bilgilerle ilişkili olan daha önce edindikleri bilgileri kıyasladıklarını, bilgilerin uyumlu olup olmadıklarını kontrol ettiklerini ifade etmişlerdir. Aşağıda örnek ifadelere yer verilmiştir.

B1: “...mesela dinozorlarla ilgili daha önce izlediğim şeyler var benim. Şimdi bu yazıyı okurken orda izlediklerimle bunda anlatılanlar aynı mı farklı mı diye karşılaştıııım ben okurken..."

Tablo 5’te öğrenme güçlüğü yaşayan okuyucuların okuma sırasında sergiledikleri davranışlar sunulmuştur.

Tablo 5. Öğrenme güçlüğü yaşayan okuyucuların okuma sırasında sergiledikleri davranışlar

\begin{tabular}{llcc}
\hline Tema & Kategori & Katlımcılar & f \\
\hline İzleme & Anlamı bilinmeyen kelimeleri sorma & Ö1, Ö2, Ö5, Ö6, Ö8 & 5 \\
\hline
\end{tabular}

Odak grup görüşmesi ile elde edilen verilerin analizi sonucunda, izleme teması ve bu tema altında anlamı bilinmeyen kelimeleri sorma kategorisi elde edilmiştir. Aşağıda elde edilen tema ve kategori açıklanmıştır. 


\section{İzleme}

\section{Anlamı bilinmeyen kelimeleri sorma (f:5)}

Öğrenme güçlüğü olan okuyucuların beşi, okuma sırasında anlamını bilmedikleri kelimelerle karşılaştklarında bu kelimelerin anlamını eğer sınıfta bir okuma yapıyorlarsa öğretmenlerine ya da sıra arkadaşlarına sorarak öğrenmeye çalıştklarını ifade etmişlerdir.

Ö2: “...okuduklarımda anlamını bilmediğim kelimeler çok oluyor. Onlar olunca anlamıyorum. Onları öğretmene sorarım. Evde soracak kimse olmaz. Ama evde ödev verilen yerleri okumak istemiyorum..."

Sonuç olarak, başarılı okuyucuların metni anlamak için okuma sırasında çok çeşitli bilişsel ve üstbilişsel strateji kullandığı, buna karşın öğrenme güçlüğü olan öğrencilerin okuma sırasında sadece bir strateji kullandığı görülmektedir.

Başarılı okuyucuların okuma sonrasında sergiledikleri davranışlara ilişkin elde edilen bulgular Tablo 6'da sunulmuştur.

Tablo 6. Başarılı okuyucuların okuma sonrasında sergiledikleri davranışlar

\begin{tabular}{llcc}
\hline Tema & Kategori & Katlımcllar & $\mathrm{f}$ \\
\hline \multirow{2}{*}{ Tekrar okuma } & Tekrar okumak & B3, B5, B6 & 3 \\
& Önemli bölümleri tekrar okumak & B1, B2, B3, B4, B5, B6, B8 & 7 \\
\hline \multirow{2}{*}{ Çıkarım yapmak } & Ana fikri bulmak & B1, B2, B3, B4, B5, B6, B7, B8 & 8 \\
& Farklı bir son yazma & B1, B2, B3, B5, B6, B8 & 6 \\
\hline \multirow{2}{*}{ Pekiştirmek } & Özetlemek & B1, B2, B3, B4, B5, B6, B8 & 7 \\
& Başkasına anlatmak & B1, B2, B4, B5, B7 & 5 \\
\hline
\end{tabular}

Odak grup görüşmesi ile elde edilen verilerin analizi sonucunda başarılı okuyucuların ifadelerine bağlı olarak, tekrar okuma, çıkarım yapma ve pekiştirme temaları elde edilmiştir. Bu temalar altında alt farklı kategori oluşturulmuştur. Aşağıda tema ve kategorilerin açıklamalarına yer verilmiştir.

\section{Tekrar okuma}

\section{Tekrar okumak (f:3)}

Başarılı okuyucuların üçü, bir metni okuduktan sonra vakitleri varsa, metinde anlatlanlar ilgilerini çekmişse ya da metinde çok bilgi olduğunu düşünüyorlarsa herhangi birini gözden kaçırmış olmamak için metni tekrar okuyacaklarını ifade etmişlerdir.

B6: “...çok eğlenceli olan bizim için çok faydalı bilgileri olan hikayeleri iki kere okurum. Çünkü önemli

bilgileri daha iyi öğrenirim."

\section{Önemli bölümleri tekrar okumak (f:7)}

Başarılı okuyucuların yedisi, metni baştan sona okumak yerine önemli olan kısımları okuyarak vakit kazanacaklarını bu vakitte başka bir metin okuyabileceklerini ifade etmişlerdir.

B3: “...okuduğum yazılarda önemli yerler oluyor. Sonra oraları bir kere daha okuyorum daha iyi anlamak için..."

\section{Çıkarım yapma}

\section{Ana fikri bulmak (f:8)}

Başarılı okuyucuların sekizi, bir metni okuduktan sonra o metinin ana fikrini belirlediklerini ve bu ana fikirden hareketle günlük hayata ya da okul hayatına dair kendilerine çıkarımlar/uyarlamalar yaptıklarını ifade etmişlerdir.

B2: “...bir yazıyı okuduktan sonra nasıl bir ders çıkarmamızı istediğini bulurum. Bir de ana fikrini bulurum"

Farklı bir son yazmak (f:6)

Başarılı okuyucuların altısı, okudukları metne farklı bir son yazarak metnin verdiği mesajı değiştirdiklerini ve bununla metnin orijinal halini kıyasladıklarını ifade etmişlerdir. 
B8: “...okuduğum bazı hikayelerin sonları hep birbirine benziyor. Ben olsam sonunu böyle yazardım diyorum."

\section{Pekiştirme}

\section{Özetlemek (f:7)}

Başarılı okuyucuların yedisi, okuma sonrasında metinde anlatılanları özetleyerek kısaca önemli bilgileriyle hatırladıklarını böylece daha kalıc bilgiler edindiklerini ifade etmişlerdir.

B5: “...okuduğum tüm kitaplar için özet defteri tutuyorum. Okuduktan sonra oraya özetini yazıyorum.”

\section{Başkasına anlatmak (f:5)}

Başarılı okuyucuların beşi, okudukları metinden edindikleri bilgileri ya da metinde anlatılan hikayeyi ve hikayeden çıkardıkları sonucu, verilmeye çalışılan mesajı sıra arkadaşlarına, mahalledeki apartmandaki arkadaşlarına, kardeşlerine ya da anne-babasına anlattıklarını böylece anladıklarının daha kalıcı olduğunu ifade etmişlerdir.

B7: “... okuduğum kitapları, haberleri anneme anlatiyorum. O bana soru soruyor bazen o zaman daha çok anlatiyorum. Anneme anlattıklarım daha çok aklımda kalıyor."

Tablo 7'de öğrenme güçlüğü yaşayan okuyucuların okuma sonrasında sergiledikleri davranışlar sunulmuştur.

Tablo 7. Öğrenme güçlüğü yaşayan okuyucuların okuma sonrasında sergiledikleri davranışlar

\begin{tabular}{llcc}
\hline Tema & Kategori & Katlımcılar & $f$ \\
\hline \multirow{3}{*}{ Tekrar okuma } & Son bölümü tekrar okuma & Ö1, Ö2, Ö3, Ö6, Ö7, Ö8 & 6 \\
& Özeti okuma & Ö1, Ö2, Ö3, Ö4, Ö6, Ö7 & 6 \\
& Illgi çekici konuyu tekrar okuma & Ö1, Ö3, Ö4, Ö7, & 4 \\
\hline
\end{tabular}

Verilerin analizi sonucunda öğrenme güçlüğü yaşayan öğrencilerin ifadelerine göre tekrar okuma teması ve bu tema altında üç farklı kategori elde edilmiştir. Aşağıda tema ve kategorilerin açıklaması verilmiştir.

\section{Tekrar okuma}

\section{Son bölümü tekrar okuma (f:6)}

Öğrenme güçlüğü olan okuyucuların altısı, okuma sonrasında metinde anlatılanları anlayamamaları durumunda metnin son paragrafinı ya da son birkaç cümlesini tekrar okuduklarını ifade etmişlerdir.

O1: “... okuduktan sonra anlamadıysam sondaki cümleleri tekrar okurum.”

\section{Özeti okuma (f:6)}

Öğrenme güçlüğü yaşayan öğrencilerin altısı, okuma sonrası süreçte metni anlamamaları durumunda eğer okuduklarım metnin/kitabın özeti varsa onu tekrar okuduklarını belirtmişlerdir.

O3: “...okuduktan sonra anlamadıysam baştan sona okumak zor gelir tekrar. Özetini çıkardıysa birisi onu okurum, bazı kalın kitapların daha inceleri oluyor, kısa kısa anlatan onları okurum anlamadıysam"

ilgi çekici konuyu tekrar okuma (f:4)

Öğrenme güçlüğü yaşayan okuyucuların dördü, okudukları metini anlamamaları durumunda eğer metinde anlatılan olay ya da sunulan bilgiler ilgilerini çekiyorsa metni tekrar okuyabileceklerini ifade etmişlerdir.

Ö7: “...bir şey okurken çok sıkılıyorum. Derste öğretmen kitaptaki yerleri okumamızı istediğinde okuyormuş gibi yapıyorum bir kısmını. Anlamadıysam tekrar okurum belki ama konu ilgimi çektiyse okurum..."

Sonuç olarak, başarılı okuyucuların metni anlamak için okuma sonrasında çok fazla bilişsel ve üstbilişsel strateji kullandığı, buna karşın öğrenme güçlüğü olan öğrencilerin sınırlı sayıda bilişsel ve üstbilişsel strateji kullandığı ifade edilebilmektedir.

\section{Tartışma ve Sonuç}

Bu araştırmada, başarılı okuyucular ile öğrenme güçlüğü olan öğrencilerin kullandıkları bilişsel ve üstbilişsel stratejiler karşılaştırmalı olarak araştırılmıştır. Araştırmanın bulguları, öğrenme güçlüğü olan öğrencilerin okuma öncesinde, sırasında ve sonrasında çok az ve yetersiz düzeyde bilişsel ve üstbilişsel strateji kullandıklarını göstermektedir. Diğer 
taraftan başarılı okuyucuların ise verilen metni anlamak için okuma öncesinde, sırasında ve sonrasında daha fazla stratejiden yararlandığı belirlenmiştir. Bu sonuç, önceki araştırmaların (Anastasiou ve Griva, 2009; Botsas ve Padeliadu; 2003; Gelen, 2003; Ehrlich, Kurtz-Costes ve Loridant, 1993; Kavale ve Schreiner, 1979; Kletzien, 1991; Kuruyer ve Özsoy, 2015; Lau, 2006; Lau ve Chan, 2003; Wigent, 2013) bulguları ile uyumludur. Örneğin, Botsas ve Padeliadu (2003) yapmış oldukları çalışmada, normal gelişim gösteren öğrencilerin öğrenme güçlüğü olan öğrencilere göre anlama stratejilerini daha çok kullandığı ve bu stratejilerin çeşitliliğinin daha fazla olduğu belirlemiştir. Kuruyer ve Özsoy (2016)'un çalışmasında ise zayıf okuyucuların tersine, başarılı okuyucuların okuma öncesinde okuma amacını belirdiği, neden okuması gerektiğini anladığı ve uygun strateji seçtiği; okuma sırasında, beklenti oluşturdukları ve tahminde bulundukları, güçlükler yaşadığında iyileştirme stratejileri kullandıkları, bağlamdan yararlanarak yeni kelimelerin anlamını öğrendikleri, anlamayı izledikleri, yeni ve eski bilgileri organize ettikleri görülmüştür. Öğrenme güçlüğü olan öğrencilerin pasif okuyucular olmalarının ve bilişsel ve üstbilişsel stratejileri kendi kendilerine kazanamamalarının bu sonucun ortaya çıkmasında etkili olduğu söylenebilir. Dolayısıyla okullarda öğretmenlerin okuduğunu anlamada güçlük yaşayan öğrencilerin anlama becerilerini geliştirebilmeleri için, bu öğrencilere doğrudan bilişsel ve üstbilişsel strateji öğretimi yapması önemli olacaktır.

Katılımcıların okuma öncesindeki davranışlarına bakıldığında, başarılı okuyucuların metni anlamak için geçmiş bilgilerini aktifleştirmek ve metinle ilgili tahminde bulunmaya yönelik çeşitli stratejiler kullanırken; öğrenme güçlüğü olan öğrencilerin sadece görsellerden yararlanarak tahminde bulundukları belirlenmiştir. Okuma öncesinde kullanılan stratejiler, öğrencinin kendi yaşantıları ile okunacak metin arasında bağ kurmasını ve metni okumadan önce metni anlamasını kolaylaştracak etkinlikleri yapmasını sağlamaktadır (Klingner ve Vaughn, 2004). Okuyucuların bu bağı kuramaması veya var olan bilgilerini harekete geçirememesi anlama sürecini olumsuz şekilde etkileyebilmektedir. Ayrıca araştırmada başarılı okuyucular okuma öncesinde ilgilerini çeken ve uzun metinler tercih ederken, öğrenme güçlüğü olan öğrenciler genellikle kısa ve dersleriyle ilgili metinler tercih etmiştir. Arya (1998) yapmış olduğu çalışmada, zayıf okuyucuların kısa metinleri orta ve uzun metinlere göre daha az hatayla ve hızlı okuduklarını, ayrıca kısa metinleri anlama düzeylerinin orta ve uzun metinlere göre yüksek olduğunu belirlemiştir. Bu durum öğrenme güçlüğü olan öğrencilerin okumaya yönelik geçmişte yaşamış oldukları olumsuz deneyimler ve dolayısıyla düşük motivasyonları ile açıklanabilir (Gersten vd., 1998). Öğrenme güçlüğü olan öğrencilerin okuma sürecine başarısız olarak başlamaları ileriki süreçlerde de okumaya karşı olumsuz tutumlar sergilemelerine neden olabilmektedir. Okumaya yönelik bu tutumların okuma miktarını, okuma miktarının ise okuduğunu anlamayı önemli ölçüde yordadığı belirtilmektedir (Guthrie ve Wigfield, 1999). Diğer taraftan başarılı okuyucuların uzun ve ilgilerine göre metinler seçmeleri okuyacakları metinle ilgili beklenti oluşturduklarını ve okumaya yönelik olumlu tutum sahibi olduklarını göstermektedir.

Katılımcıların okuma sırasındaki davranışlarına bakıldığında, başarılı okuyucuların metni anlamak için tahmin etmeye, anlamlarını izlemeye, görsel değerlendirmeye ve geçmiş bilgilerle kıyaslamaya yönelik stratejiler kullandıkları, öğrenme güçlüğü olan öğrencilerin ise metni anlamlandırmak için sadece anlamını bilmedikleri kelimeleri sordukları belirlenmiştir. Bu sonuçtan hareketle başarılı okuyucuların anlamalarını izlemeye ve bu bilgileri anlamlı hale getirmeye yönelik stratejiler kullandıkları tespit edilmiştir. Diğer taraftan öğrenme güçlüğü olan öğrencilerin anlamını bilmedikleri kelimeleri sormaları her ne kadar başarılı okuyucuların anlama ulaşmak için kullanılan bir strateji olsa da, öğrenme güçlüğü olan öğrencilerin sadece metindeki kelimelerin anlamına odaklanmaları metnin anlam bütünlüğünü kaçırmalarına, metinde var olan bilgileri geçmiş bilgileriyle ilişkilendirmelerine ve anlamalarını izlemelerine engel olabilmektedir. Oysaki başarılı okuyucular metin içerisinde anlamını bilmedikleri kelimelere takılmak yerine, metni bir bütün olarak anlamaya yoğunlaşmaktadır (Oakhill, Hart ve Samols, 2005). Alanyazın incelendiğinde de başarılı okuyucuların anlamalarını izlemeye yönelik stratejiler kullandıkları, anlamını bilmedikleri bir kelime karşılaştıklarında anlamını metin içerisinden çıkardıkları ve okuduklarını anlama da başarııızık yaşadıklarında bu fark edebildikleri, buna yönelik stratejiler geliştirdikleri belirtilmektedir (Kletzien, 1991; McNamara, Ozuru, Best ve O’Reilly, 2012).

Katılımcıların okuma sonrasındaki davranışlarına bakıldığında, başarılı okuyucuların metni anlamak için tekrar okuma, çıkarım yapma ve anlamalarını pekiştirmeye yönelik stratejiler kullandığı gözlemlenirken; öğrenme güçlüğü olan öğrencilerin sadece tekrar okuma stratejisini kullandığı belirlenmiştir. Benzer olarak Cook (1989), bilişsel ve üst bilişsel becerilere sahip okuyucuların okuma sonrasında okuduklarını anlatabildiklerini, değerlendirme yaptıklarını, ana fikri bulmada başarılı olduklarını, diğer taraftan zayıf bilişsel ve üstbilişsel becerileri olan okuyucuların ise bunları yapamadıklarını belirtmektedir (akt. Gelen, 2003). Okuma sonrasında okuyuculardan beklenen temel davranışlardan biri okuduklarını anlamaya yönelik değerlendirmeler yapabilmeleridir. Bu doğrultuda, metni anlamadıklarında veya daha iyi anlamak için her iki grup da tekrar okuma stratejisini kullanmıştr. Diğer taraftan öğrenme güçlüğü olan öğrencilerin okuma sonrası anladıklarını pekiştirmeye ve anladıklarından çıkarım oluşturmaya yönelik stratejileri sınırlı düzeyde kullanmalarının anlama süreçlerini olumsuz etkileyeceğinden söz edilebilir. 
Tüm sonuçlar birlikte ele alındığında, özetle, başarılı okuyucuların okuma öncesi, sırası ve sonrası birçok bilişsel ve üstbilişsel stratejiyi birlikte kullandığı, daha uzun ve zor metin seçtikleri belirlenmiştir. Diğer taraftan öğrenme güçlüğü olan öğrencilerin okuma öncesi, sırası ve sonrası pek fazla bilişsel ve üstbilişsel strateji kullanmadığı, kısa ve kolay metinler seçtikleri tespit edilmiştir. Bu araştırmanın sonuçlarını değerlendirirken göz önünde bulundurulması gereken bazı sınırlıııları da vardır. Illk olarak, strateji kullanımının değerlendirilmesi sekiz başarılı okuyucu ve sekiz öğrenme güçlüğü tanısı almış öğrenci yapılmıştır. Bu durum bulguların genellenmesini sınırlandırmaktadır. İkinci olarak başarılı okuyucuların belirlenmesi sürecinde öğretmen görüşü ve ders başarılı ile sınırlıdır. İleri araştırmalara ve uygulamalara yönelik olarak ise, daha büyük gruplarla bu karşılaştırma yapılması önerilebilir. Bunun yanı sıra üstün yetenekli tanısı almış öğrenciler ile öğrenme güçlüğü olan öğrencilerin bilişsel ve üstbilişsel strateji kullanmaları karşılaştırılabilir.

\section{Kaynakça}

Anastasiou, D., \& Griva, E. (2009). Awareness of reading strategy use and reading comprehension among poor and good readers. İlköğretim Online, 8(2), 283-297.

Arya, P. (1998). The effects of varying text length on the oral reading miscues of good and poor readers in grade two (Doctoral Dissertation). Available from ProQuest Dissertations and Theses database. (UMI No. 9905239)

Bogdan, R. C., \& Biklen, S. K. (1992). Qualitative research for education: an introduction to theory and methods. Boston: Allyn and Bacon.

Botsas, G., \& Padeliadu, S. (2003). Goal orientation and reading comprehension strategy use among students with and without reading difficulties. International Journal of Educational Research, 39(4), 477-495.

Buxton, J. A. (2017). An investigation of the relationships among high school students' reading comprehension strategy instruction, strategy use, attitudes, and achievement (Doctoral Dissertation). Available from ProQuest Dissertations and Theses database. (UMI No. 10686076)

Durkin, D. (1993). Teaching them to read (6th ed.). Boston: Allyn \& Bacon.

Edmonds MS, Vaughn S, Wexler J, Reutebuch CK, Cable A, Tackett K, et al. A synthesis of reading interventions and effects on reading outcomes for older struggling readers. Review of Educational Research. 2009;79(1):262-300.

Ehrlich, M. F., Kurtz-Costes, B., \& Loridant, C. (1993). Cognitive and motivational determinants of reading comprehension in good and poor readers. Journal of Reading Behavior, 25(4), 365-381.

Espinoza, M. F., \& Márquez Cruz, S. D. (2015). The teaching strategies in the Teaching-Learning proccess of reading skill in eleventh grade, Doctoral dissertation, Universidad Nacional Autónoma de Nicaragua, Managua.

Fırat, T. (2017). Okuma öncesinde, sırasında ve sonrasında düşün (3D) stratejisi öğretiminin öğrenme güçlüğü olan öğrencilerin okuduklarını anlama becerilerine etkisi. Yayınlanmamış Doktora Tezi, Ankara Üniversitesi, Ankara.

Ford, M. P., \& Opitz, M. F. (2011). Looking back to move forward with guided reading. Reading Horizons, 50(4), 225-240.

Gaddy, S.A. (2004). Teaching text-structure strategies to postsecondary students with learning disabilities to compare their reading comprehension performance on expository text (Doctoral Dissertation). Available from ProQuest Dissertations and Theses database. (UMI No. 3196666)

Gelen, i. (2003). Bilişsel farkındalık stratejilerinin Türkçe dersine ilişkin tutum, okuduğunu anlama ve kalıılığa etkisi. Yayımlanmamış Doktora Tezi, Çukurova Üniversitesi. Adana.

Gersten, R., Williams, J. P., Fuchs, L., Baker, S., Koppenhaver, D., Spadorcia, S., \& Harrison, M. (1998). Improving reading comprehension for children with disabilities: A review of research. Final report. Washington, DC: Special Education Programs (SD/OSERS).

Gersten, R., Fuchs, L. S., Williams, J. P., \& Baker, S. (2001). Teaching reading comprehension strategies to students with learning disabilities: A review of research. Review of Educational Research, 71(2), 279-320.

Guthrie, J. T., \& Wigfield, A. (1999). How motivation fits into a science of reading. Scientific Studies of Reading, 3(3), 199-205.

Guthrie, J. T., Hoa, A. L. W., Wigfield, A., Tonks, S. M., Humenick, N. M., \& Littles, E. (2007). Reading motivation and reading comprehension growth in the later elementary years. Contemporary Educational Psychology, 32, 282-313.

Güldenoğlu, B., Kargin, T., ve Miller, P. (2013). Okuma güçlüğü olan ve olmayan öğrencilerin cümle anlama becerilerinin incelenmesi. Türk Psikoloji Dergisi, 30(76), 82.

Hallahan, D.P., Kauffman, J.M., \& Lloyd, J.W. (1996). Introduction to learning disabilities. Boston: Allyn and Bacon.

Hummel, S. (2000). Developing comprehension skills of secondary students with specific learning difficulties. Australian Journal of Learning Difficulties, 5(4), 22-27.

Jitendra, A. K., Hoppes, M.K., \& Xin, Y. P. (2000). Enhancing main idea comprehension for students with learning problems: The role of a summarization strategy and self-monitoring instruction. The Journal of Special Education, 34(3), 127-139.

Johnson, S. D. (1997). Examining the validity structure of qualitative research. Education. 118(3), 282-292.

Kavale, K., \& Schreiner, R. (1979). The reading processes of above average and average readers: A comparison of the use of reasoning strategies in responding to standardized comprehension measures. Reading Research Quarterly, 15(1), 102-128.

| Kastamonu Eğitim Dergisi, 27(2), 2019| 
Kendeou, P., \& van den Broek, P. (2007). The effects of prior knowledge and text structure on comprehension processes during reading of scientific texts. Memory and Cognition, 35(7), 1567-1577.

Kitzinger, J. \& Farquhar, C. (1999). The analytical potential of 'sensitive moments' in focus group discussions. In R. Barbour \& J. Kitzinger (Eds), Developing focus group research: Politics, theory and practice (pp. 156-172). London: SAGE.

Kletzien, S. B. (1991). Strategy use by good and poor comprehenders reading expository text of differing levels. Reading Research Quarterly, 26, 67-86.

Klingner, J.K., \& Vaughn, S. (2004). Strategies for struggling second-language readers. In T.L. Jetton \& J.A. Dole (Eds.), Adolescent literacy research and practice (pp. 183-209). New York: Guilford.

Kuruyer, H. G., \& Özsoy, G. (2015). İyi ve zayıf okuyucuların üstbilişsel okuma becerilerinin incelenmesi: Bir durum çalışması. Kastamonu Eğitim Dergisi, 24(2), 771-788.

Lau, K. L. (2006). Reading strategy use between Chinese good and poor readers: A think-aloud study. Journal of Research in Reading, 29(4), 383-399.

Lau, K. L., \& Chan, D. W. (2003). Reading strategy use and motivation among Chinese good and poor readers in Hong Kong. Journal of Research in Reading, 26(2), 177-190.

León, J. A., \& Carretero, M. (1995). Intervention in comprehension and memory strategies: Knowledge and use of text structure. Learning and instruction, 5(3), 203-220.

Livingston, J. A. (2003) Metacognition: An overview. Retrieved January 20.01.2018, https://files.eric.ed.gov/fulltext/ED474273.pdf

Mahdavi, J. N., \& Tensfeldt, L. (2013). Untangling reading comprehension strategy instruction: Assisting struggling readers in the primary grades. Preventing School Failure: Alternative Education for Children and Youth, 57(2), 77-92.

Maine, F. (2013). How children talk together to make meaning from texts: A dialogic perspective on reading comprehension strategies. Literacy, 47(3), 150-156.

Mason, L. H. (2004). Explicit self-regulated strategy developmentversus reciprocal questioning: Effect on informational reading comprehension among struggling readers. Journal of Educational Psychology, 96, 283-296.

Mastropieri, M. A., Scruggs, T. E., \& Graetz, J. E. (2003). Reading comprehension instruction for secondary students: Challenges for struggling students and their teachers. Learning Disability Quarterly, 26, 103-116.

McNamara, D. S., Ozuru, Y., Best R., \& O’Reilly, T. (2012). Pronged comprension strategy framework. McNamara, D. S. (Ed.). Reading comprehension strategies: Theories, interventions, and technologies (pp. 465-496). Mahwah, NJ: Erlbaum.

Miles, M. B. \& Huberman, A. M. (1994). Qualitative data analysis: Asourcebook of new methods. California;SAGE Publications.

Oakhill, J., Hartt, J., \& Samols, D. (2005). Levels of comprehension monitoring and working memory in good and poor comprehenders. Reading and Writing, 18, 657-86.

Pressley, M. (2002). Metacognition and self-regulated comprehension. What Research Has to Say About Reading Instruction, 3, $291-309$.

Pressley, M., \& Afflerbach, P. (1995). Verbal protocols of reading: The nature of constructively responsive reading. Routledge.

Pressley, M., \& Gaskins, I. (2006). Metacognitively competent reading comprehension is constructively responsive reading: How can such reading be developed in students? Metacognition Learning, 1(1), 99-113

Swanson, H. L. ( 1999). Reading research for students with Id: A meta-analysis of intervention outcomes. Journal of Learning Disabilities, 32, 504-532.

Swanson, E. A., \& Vaughn, S. (2010). An observation study of reading instruction provided to elementary students with learning disabilities in the resource room. Psychology in the Schools, 47(5), 481-492.

Tannenbaum, K. R., Torgesen, J. K., \& Wagner, R. K. (2006). Relationships between word knowledge and reading comprehension in third-grade children. Scientific Studies of Reading, 10(4), 381-398.

Taboada, A., Tonks, S. M., Wigfield, A., \& Guthrie, J. T. (2009). Effects of motivational and cognitive variables on reading comprehension. Reading and Writing, 22(1), 85-106.

Tilstra, J. S. (2007). What good and struggling 5 th grade readers do when reading expository text for a specific purpose: Implications for Intervention (Doctoral Dissertation). Available from ProQuest Dissertations and Theses database. (UMI No. 3263144)

Torgesen, J. K. (1982). The learning disabled child as an inactive learner: Educational implications. Topics in Learningand Learning Disabilities, 2(1), 45-52.

Wigent, C. (2013). High school readers: A profile of above average readers and readers with learning disabilities reading expository text. Learning and Individual Differences, 25, 134-140.

Yıldıım A., \& Şimşek H. (2011). Sosyal bilimlerde nitel araştırma yöntemleri. Ankara: Seçkin Yayıncılık. 